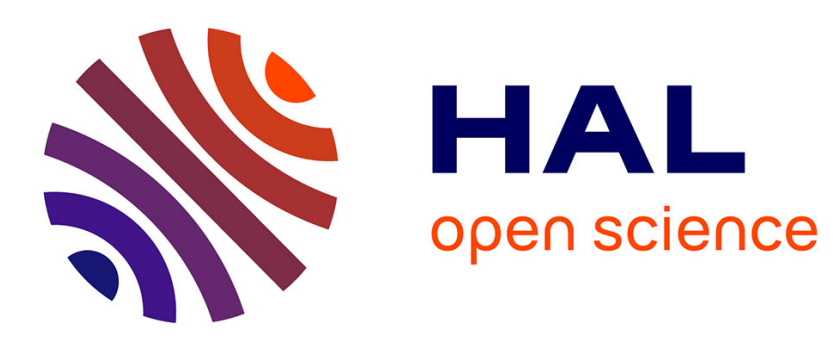

\title{
Thermal Enhancement of Magnetic Fabrics in High Grade Gneisses
}

\author{
Graham J. Borradaile, France Lagroix
}

\section{To cite this version:}

Graham J. Borradaile, France Lagroix. Thermal Enhancement of Magnetic Fabrics in High Grade Gneisses. Geophysical Research Letters, 2000, 27, pp.2413-2416. 10.1029/2000GL008522 . insu01311022

\section{HAL Id: insu-01311022 \\ https://hal-insu.archives-ouvertes.fr/insu-01311022}

Submitted on 3 May 2016

HAL is a multi-disciplinary open access archive for the deposit and dissemination of scientific research documents, whether they are published or not. The documents may come from teaching and research institutions in France or abroad, or from public or private research centers.
L'archive ouverte pluridisciplinaire HAL, est destinée au dépôt et à la diffusion de documents scientifiques de niveau recherche, publiés ou non, émanant des établissements d'enseignement et de recherche français ou étrangers, des laboratoires publics ou privés. 


\title{
Thermal enhancement of magnetic fabrics in high grade gneisses
}

\author{
Graham J. Borradaile and France Lagroix \\ Department of Geology, Lakehead University, Ontario, Canada P7B 5E1
}

\begin{abstract}
The orientation-distributions of AMS and AARM ellipsoids are non-coaxial in the Kapuskasing Zone granulites. AARM is due to the preferred orientation of magnetite which mostly postdates the silicate fabric. The AMS orientationdistribution combines susceptibility anisotropies of magnetite and the silicates. Whereas heating does not increase the bulk susceptibility, it does improve the definition of the orientationdistributions of both AMS and AARM. However, the orientation-distribution of AARM is most enhanced and therefore post-heated samples emphasize the magnetite subfabric. Thus, heating does not clarify the interpretation of the silicate fabric in this study. However, it does change the samples' AMS fabric in such a way as to reveal the magnetite subfabric which can only otherwise be detected by more tedious AARM measurements.
\end{abstract}

\section{Introduction}

Heated rock samples normally increase their bulk magnetic susceptibility, commonly due to the growth of iron oxides (Dunlop, 1974; Thompson and Oldfield, 1986). Moreover, the anisotropy of magnetic susceptibility may be increased, or the principal directions more tightly grouped after a sample has been heated. It is presumed that heating creates iron oxides that mimetically overgrow the natural petrofabric, or relaxes stresses of magnetite domain structures thereby potentially increasing AMS (Jeleńska and Kądzialko-Hofmokl, 1990). Conventional wisdom suggests that increasing anisotropy or even bulk susceptibility improving the alignment of principal directions could simplify the recognition of a feeble AMS fabric (Kropáček, 1976; Perarnau and Tarling, 1985; Urrutia-Fucugauchi, 1981). In turn, this should facilitate petrofabric interpretation and discrimination of sedimentary, paleocurrent, magmatic or tectonic flow patterns in rocks (Borradaile and Henry, 1997; Hrouda, 1982; Rochette et al., 1992; Stephenson et al., 1986).

It has not usually been specified whether the initial weak fabric results from low bulk susceptibility, weak anisotropy, or competing substantial magnetic anisotropies due to different fabric forming events (e.g., bedding and schistosity). Mimetic overgrowth of iron oxides during in-atmosphere heating is a reasonable assumption in the first two cases but is more

Copyright 2000 by the American Geophysical Union.

Paper number 2000GL008522.

0094-8276/00/2000GL008522\$05.00 doubtful in the latter case. For example, principal susceptibility directions of some slates are changed erratically after heating, probably due to the fortuitous selective enhancement of a cryptic subfabric (Borradaile and Henry, 1996, fig.4). The interpretation of such enhanced fabrics may not be worth the effort if the relevant importance of the initial competing bedding and tectonic subfabrics cannot be determined.

To test the success of fabric enhancement, we selected tectonites from the high grade granulite facies lower crustal rocks exposed in the Kapuskasing Structural Zone (KSZ) of northern Ontario. An absence of a vestigial primary fabric, the presence of single tectonic fabric and simple mineralogy with abundant mafic silicates makes them ideal to monitor the effects of heating on magnetic anisotropy. The KSZ upthrusts lower crustal rock from an original depth of $\sim 30 \mathrm{~km}$, in the Archean Superior Province of the Canadian Shield (Percival and West, 1994). The KSZ was metamorphosed to upper amphibolite and granulite facies under pressures and temperatures of $0.7-1.0 \mathrm{GPa}$ and $650^{\circ} \mathrm{C}-770^{\circ} \mathrm{C}$ (Percival, 1983). Geochronological (Krogh and Moser, 1994) and paleomagnetic (Symons and Vandall, 1990; Symons et al., 1994) studies identified two stages of uplift at about 2500$2454 \mathrm{Ma}$ and 1950-1850 Ma. The second stage of uplift was accompanied by dextral shearing and block tilting. The KSZ is characterized by positive gravity and magnetic anomalies. Our samples represent an homogeneous structural domain in the granulite facies lower crustal rocks, adjacent to the thrust which exhumed the KSZ.

\section{Interpretation of Initial Unheated Magnetic Fabrics}

Anisotropy of low field magnetic susceptibility (AMS), determined in a Sapphire Instruments SI2B unit, reveals a well defined orientation-distribution of principal susceptibilities $\left(\mathrm{k}_{\mathrm{MAX}} \geq \mathrm{k}_{\mathrm{INT}} \geq \mathrm{k}_{\mathrm{MIN}}\right)$ with a ENE-WSW lineation due to a feeble alignment of pyroxene $k_{\text {MAX }}$ (Fig.1a) with some contribution from magnetite (Borradaile et al., 1999). $k_{\mathrm{INT}}$ and $k_{\mathrm{MIN}}$ fall along broad partial girdles reflecting the poor ability of pyroxenes to define a foliation, but rather form a zone-axis about the lineation. Nevertheless, the tensor-mean $\mathbf{k}_{\text {MIN }}$ is nearly vertical, indicating that the weakly defined magnetic foliation is subhorizontal. Anisotropy of anhysteretic remanence (AARM, e.g., Jackson, 1991) isolates the samples' magnetite preferred dimensional orientation-distribution (Fig.1b). $A_{\text {MAX }}$ is almost as well defined as the $k_{\text {MAX }}$ but plunges gently WSW rather than being subhorizontal. The absence of substantial overlap of the $95 \%$ confidence cones 
for $A_{\text {MAX }}$ and $k_{\text {MAX }}$ corroborates the conclusion that the rocks experienced a noncoaxial strain history, in which magnetite traps a later portion of the kinematic pattern, perhaps during part of the regional uplift (Borradaile et al., 1999). $A_{\mathrm{INT}}$ and $A_{\text {MIN }}$ scatter more broadly on similar partial girdles with the tensor-mean $A_{\text {MIN }}$ indicating that a poorly defined AARMfoliation plane dips gently NNW.

\section{Thermal Enhancement of Magnetic Fabrics}

Sixty samples were heated in air, cooled and their AMS remeasured after heating to temperatures of $100,200,300$, 400,500 and $600^{\circ} \mathrm{C}$ (Fig.2). The bulk susceptibility (k, in units of $\mu \mathrm{S}$ ) changes relatively little until $400^{\circ} \mathrm{C}$ beyond which it is eventually reduced by about $25 \%$ (Fig.3). This suggests that some original magnetite is destroyed during heating, although it does not preclude the generation of new magnetite from the breakdown of paramagnetic silicates. It is usually believed that the latter effect may enhance the AMS fabric of paramagnetic silicates simply by amplifying the magnitude of the signal. Indeed, in this study the scalar means of the anisotropy parameters $(\mathrm{Pj}=$ eccentricity and $\mathrm{Tj}$ = shape) change little as the samples are progressively heated (see Fig.2, inset). However, the orientation-distribution of AMS for the suite of samples changes considerably (Fig.2), upon which we now comment.

An important distinction must be made between the AMS of an individual sample, and the tectonic symmetry of an orientation-distribution of AMS from many sites grouped on a stereogram. The individual AMS measurement, and even the scalar average of the $\mathrm{Pj}$ and $\mathrm{Tj}$ values for a suite of samples is not necessarily related to the fabric stereoplot. The stereonet representing the fabric is a complex three-
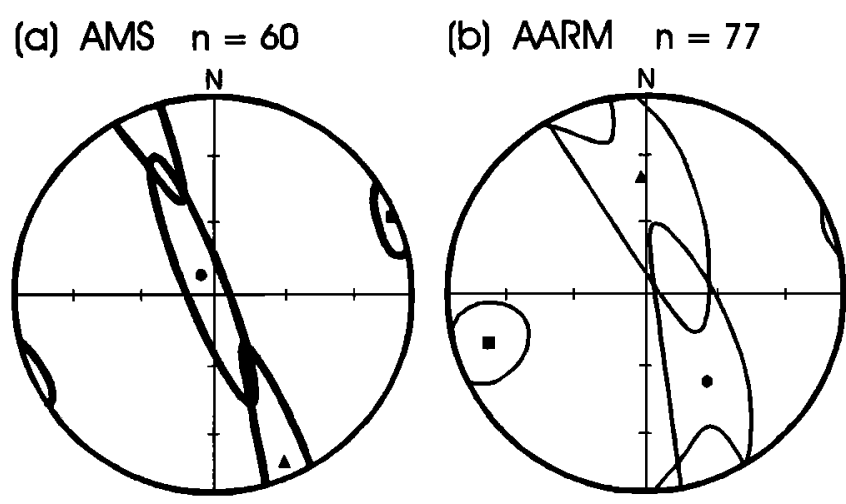

(c)
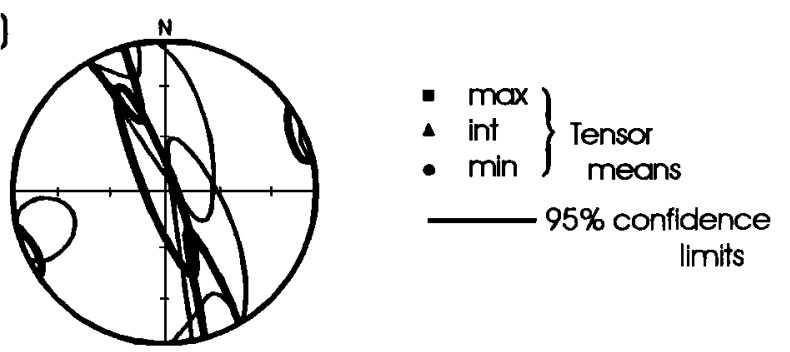

Figure 1. Tensor means of principal directions of anisotropy of (a) low field susceptibility (AMS) and of (b) anhysteretic remanence (AARM) for samples of Kapuskasing gneisses from a structurally homogeneous domain. (c) Confidence limits for AMS and AARM fabrics compared. dimensional blend of the scattered AMS ellipsoids for the samples. This concept may be familiar to structural geologists who know that an $\mathrm{S}$-tectonite $(\mathrm{Tj}=+1)$ may be defined by rod-shaped $(T j=-1)$ minerals scattered in the schistosity plane. Also, an L-tectonite may be composed of planar minerals arranged with their poles in a girdle (Flinn, 1965). Similarly, the shapes of AMS-ellipsoids (defined by $\mathrm{Pj}, \mathrm{Tj}$ ) for individual samples, and even the scalar average for all sites may be incompatible with the symmetry of the orientationdistribution of AMS ellipsoids as revealed on the stereoplot (Fig.2; also Borradaile, Under Review for more complete discussion).

After heating even to $600^{\circ} \mathrm{C}$, our samples show negligible changes in the shape of their AMS ellipsoids, which remain relatively constant near $\mathrm{Tj}=0.2$ and the eccentricity increases only slightly (Fig.3e). Thus, the changes in individual sample anisotropies are negligible in this study, unlike others (e.g., Urrutia-Fucugauchi, 1981).

In contrast, heating progressively changes the orientationdistribution of AMS principal axes for the sample-suite (Fig.2), most dramatically summarized in Fig.3, after heating to $600^{\circ} \mathrm{C}$. Moreover, the linear fabric of the unheated samples (Fig. 1a) remained relatively unchanged until the samples had been heated to $400^{\circ} \mathrm{C}$ at which level the partial girdles of $k_{\mathrm{INT}}$ and $\mathrm{k}_{\mathrm{MIN}}$ became much narrower and the $\mathrm{k}_{\mathrm{MAX}}$ cluster tightened (Fig.2e). However, after heating to $500^{\circ} \mathrm{C}$, the zone-axis girdles of $k_{\mathrm{INT}}$ and $\mathrm{k}_{\mathrm{MIN}}$ reduced to clusters so that the orientation-distributions became orthorhombic. Although there is a decrease in bulk susceptibility (k, inset Fig.2) on heating, the orientation-distribution of AMS does change, implying the growth of a new iron oxide during heating. Thus, we attribute the changes in orientationdistribution of AMS for the sample suite to the partial suppression of the initial fabric, dominated by accessory magnetite, and the development of a new one produced by the interference of a new iron oxide subfabric coaxial with the original one. The new oxides must have much better constrained orientations shown by the improved definition of the post-heating orientation-distribution (Fig.3b, 3d).

The original intention of the thermal enhancement technique was to provide a single step of heating that, by increasing bulk susceptibility, would facilitate measurement of a weak anisotropy. Therefore, we should compare the preheating data directly with that after the ultimate stage of heating (Fig.3). It is true that definition of the principal directions for the orientation suite is improved both for AARM and AMS, as their confidence cones are much smaller after heating (Fig.3b, 3d). The tensor-mean directions for the sample suite are changed considerably for AMS, but change little for AARM. Thus, we infer that the AMS orientationdistribution is due to the enhancement of the AARM orientation-distribution. Whereas heating produced a tighter orientation-distribution of AMS principal directions, these only mimicked the younger, AARM fabric which is noncoaxial and has a different tectonic significance.

\section{Conclusions}

Laboratory heating up to $400^{\circ} \mathrm{C}$ tightened the orientationdistributions of AMS axes of high grade pyroxene-plagioclase gneisses although the bulk susceptibility did not change. Further heating to $600^{\circ} \mathrm{C}$ reduced bulk susceptibility by $25 \%$ from which we infer that some of the original accessory 
(a) unheated samples $n=60$

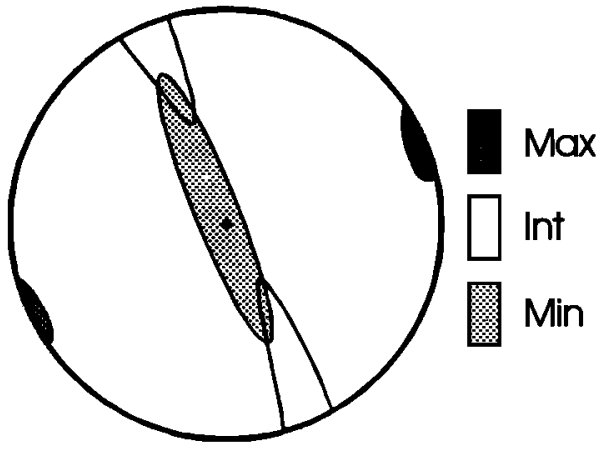

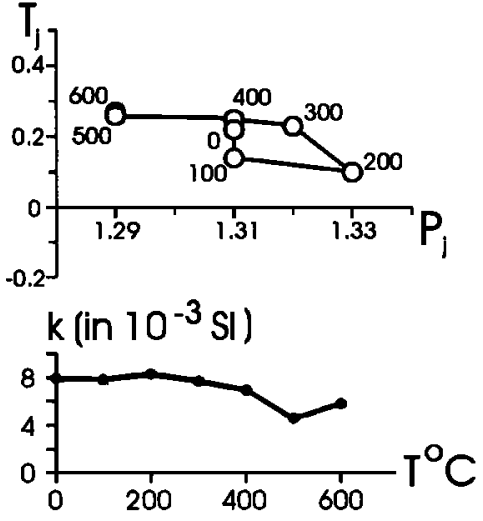

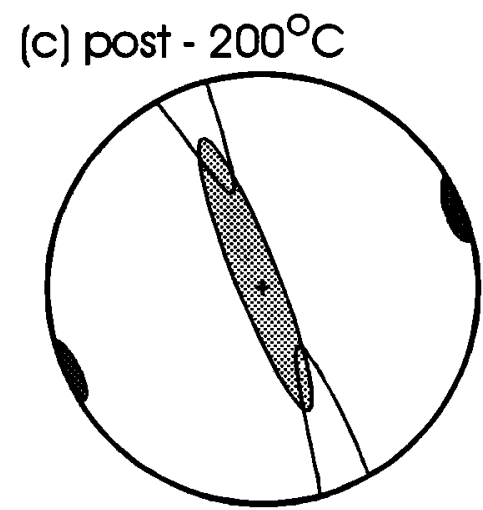

(d) post $-300^{\circ} \mathrm{C}$

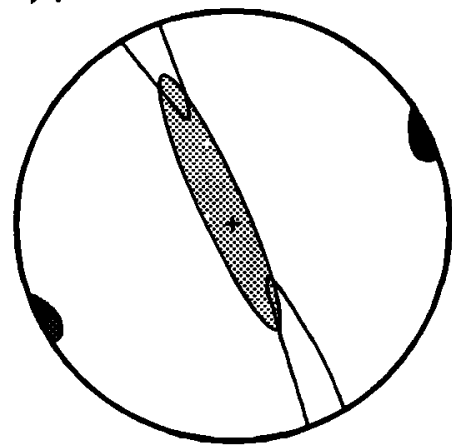

(g) post $-600^{\circ} \mathrm{C}$

(f) post $-500^{\circ} \mathrm{C}$

(e) post $-400^{\circ} \mathrm{C}$
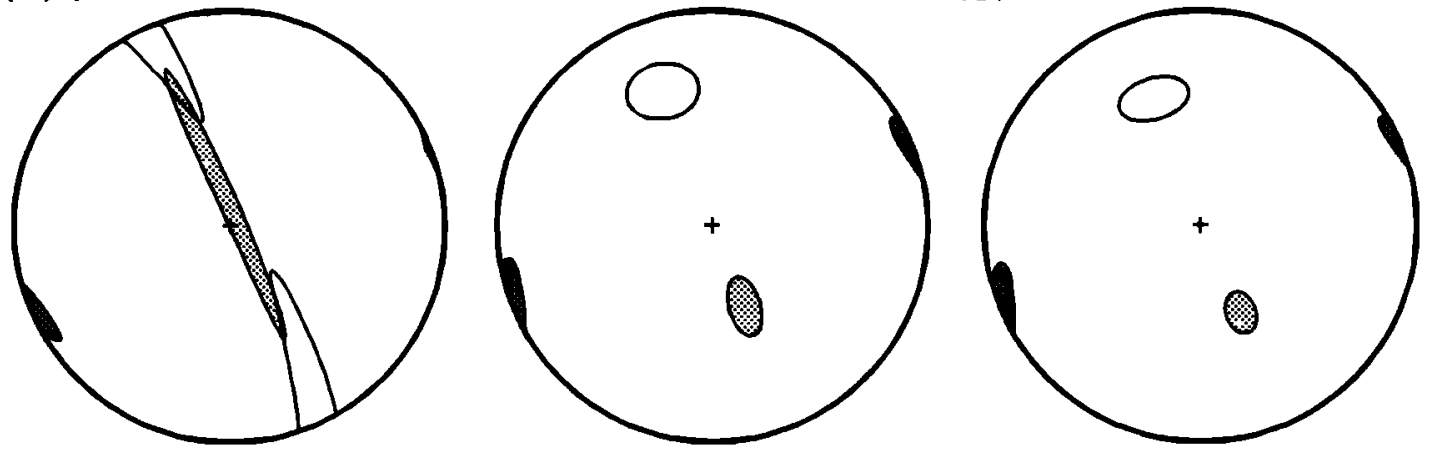

Figure 2. Thermal enhancement of AMS tightens confidence limits after heating to $400^{\circ} \mathrm{C}$. (f, g) Further heating produces an orthorhombic fabric. Inset show changes in Jelinek's (1981) anisotropy parameters (above) and bulk susceptibility (below).

magnetite was destroyed. However, this further heating changed the orientation-distribution of AMS markedly, producing an orthorhombic fabric from the pre-existing fabric which had girdles of $k_{\text {INT }}$ and $k_{\text {MIN }}$ that gave a strong linear component to the orientation-distribution. Thus, we cannot assume that heating will simply enhance an AMS orientation distribution, rendering it easier to measure. Moreover, we see that heating did not change the orientation-distribution of AARM but it did greatly enhance the definition of its principal directions by reducing its $95 \%$ confidence cones. Therefore we conclude that although original magnetite has been destroyed, heating actually enhanced the AARM fabric, not the AMS fabric. Since the two fabrics were noncoaxial (Fig.1), and developed at different stages in the tectonic history, heating would not have hindered rather than helped the interpretation of the AMS orientation distribution in this case-study. Therefore, AMS fabrics of the heated samples act as a proxy for the AARM fabrics which are obtained by much more time-consuming measurements. However, we do not recommend the substitution of AARM measurements with the AMS of post-heated samples.

Heating will only refine an AMS orientation-distribution, and preserve its directions faithfully, if the oxide subfabric is coaxial with the paramagnetic silicate fabric. More important information on kinematics is obtained by first performing AMS and AARM fabric determinations. Thermal enhancement of AMS may, as in this study, not refine the silicate orientation-distribution but emphasize and refine the noncoaxial magnetite subfabric. Finally, we draw attention to the sometimes neglected fact that the shape of AMS ellipsoids for samples may be quite unrelated to the symmetry of the orientation-distribution of the AMS axes for a suite of samples: this may be overlooked when comparing scalar averages of anisotropy parameters (e.g., $\mathrm{Pj}, \mathrm{Tj}$ ) with orientation distributions of AMS principal axes, i.e. fabric plots (Fig.2). 

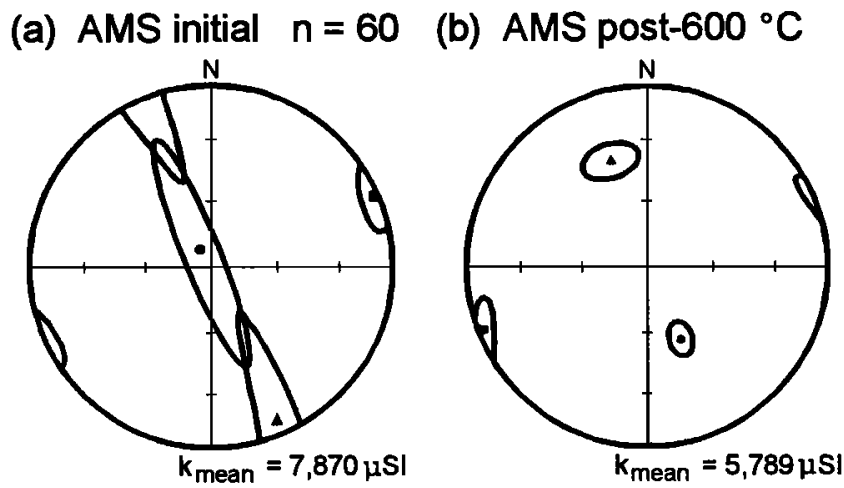

(c) AARM initial $\mathrm{n}=77$ (d) AARM post $600^{\circ} \mathrm{C}$
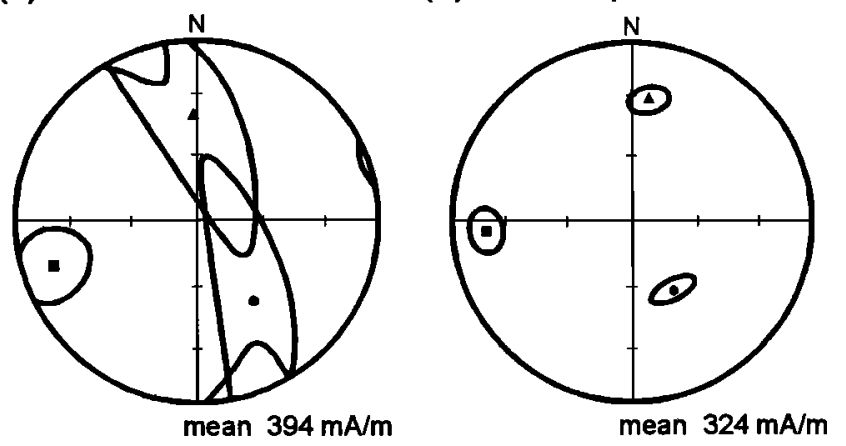

$95 \%$ confidence limit

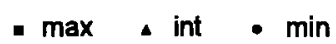

(e)

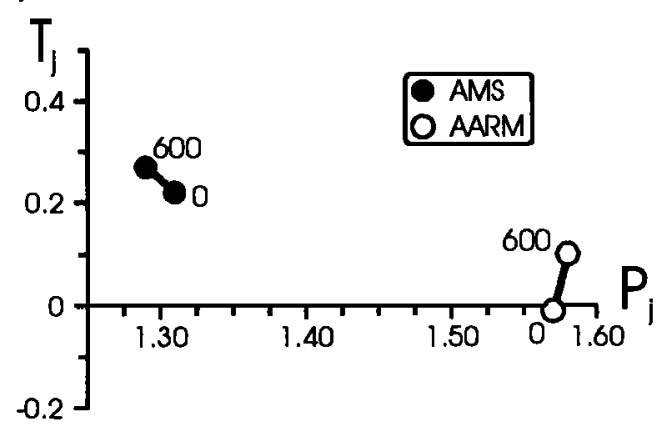

Figure 3. Initial magnetic fabrics. (a) AMS due to silicates and magnetite, (c) AARM due to magnetite. Compared with thermally enhanced AMS (b) and AARM (c). (e) The anisotropy of both AMS and AARM varies little after heating to $600^{\circ} \mathrm{C}$.

Acknowledgments. We thank the natural Sciences and Engineering Research Council of Canada (NSERC) for continuing support for this work through grants to Graham Borradaile.

\section{References}

Borradaile, G. J. Magnetic fabrics and petrofabrics: characterizing their orientation-distributions. J. Struct. Geol., Under Review.
Borradaile, G. J. and Henry, B. Tectonic applications of magnetic susceptibility and its anisotropy. Earth Sci. Rev., 42, 49-93, 1997.

Borradaile, G. J., Werner, T. and Lagroix, F. Magnetic fabrics and anisotropy-controlled thrusting in the Kapuskasing Structural Zone, Canada. Tectonophys., 302, 241-256, 1999.

Dunlop, D.J. Thermal enhancement of magnetic susceptibility. $J$. Geophys., 40, 439-451, 1974.

Flinn, D. On the Symmetry Principle and the Deformation Ellipsoid. Geol. Mag., 102, 36-45, 1965.

Hrouda, F. Magnetic anisotropy of rocks and its application in geology and geophysics. Geophys. Surv., 5, 37-82, 1982.

Jackson, M. J. Anisotropy of magnetic remanence: A brief review of mineralogical sources, physical origins, and geological applications, and comparison with susceptibility anisotropy. Pure Appl. Geophys., 136, 1-28, 1991.

Jeleńska, M. and Kądzialko-Hofmokl, M. Dependence of anisotropy of magnetic susceptibility of rocks on temperature. Phys. Earth Planet. Int., 62, 19-31, 1990.

Jelinek, V. Characterization of the magnetic fabrics of rocks. Tectonophys., 79, T63-T67, 1981.

Krogh, T. E. and Moser, D. E. U - Pb zircon and monazite ages from the Kapuskasing uplift: age constraints on deformation within the Ivanhoe Lake fault zone. Can. J. Earth Sci., 31, 1096-1103, 1994.

Kropáček, V. Changes of the magnetic susceptibility and its anisotropy of basalts by oxidation of titanomagnetites. Studia Geoph. Geod., 20, 178-185, 1976.

Perarnau, A. and Tarling, D. H. Thermal enhancement of magnetic fabric in Cretaceous sandstones. J. Geol. Soc. Lond., 142, 1029-1034, 1985.

Percival, J. A. and West, G.F. The Kapuskasing uplift: a geological and geophysical synthesis. Can. J. Earth Sci., 31, 1256-1286, 1994.

Percival, J. A. High grade metamorphism in the Chapleau-Folyette area, Ontario. Am. Mineral., 68, 667-686, 1983.

Rochette, P., Jackson, J. and Aubourg, C. Rock magnetism and the interpretation of anisotropy of magnetic susceptibility. Rev. Geophys., 30, 209-226, 1992.

Stephenson, A., Sadikun, S. and Potter, D. K. A theoretical and experimental comparison of the anisotropies of magnetic susceptibility and remanence in rocks and minerals. Geophys. $J$. R. Astr. Soc., 84, 185-200, 1986.

Symons, D. T. A. and Vandall, T. A. Paleomagnetic evidence for Proterozoic tectonism in the Kapuskasing structural zone, Onatrio. J. Geophys. Res., 95, 19,199-19,211, 1990.

Symons, D. T. A., Lewchuk, M. T., Dunlop, D. J., CostanzoAlvarez, V., Halls, H. C., Bates, M. P., Palmer, H. C. and Vandall, T. A. Synopsis of paleomagnetic studies in the Kapuskasing structural zone. Can. J. Earth Sci., 31, 1206-1217, 1994.

Thompson, R. and Oldfield, F. Environmental Magnetism, 227 pp., Allen \& Unwin, Boston, 1986.

Umutia-Fucugauchi, J. Preliminary results of the effects of heating on the magnetic susceptibility anisotropy of rocks. J. Geomag. Geoelectr., 33, 411-419, 1981.

G.J. Borradaile and F. Lagroix, Department of Geology, Lakehead University, Thunder Bay, Ontario, Canada. (Email: borradaile@lakeheadu.ca; lagr0012@tc.umn.edu)

(Received February 8, 2000; revised April 25, 2000; accepted May 18, 2000.) 